\title{
Exposure to Tobacco Advertising and Promotion among School Children Aged 13-15 in Vietnam - an Overview from GYTS 2014
}

\author{
Tran Khanh Long ${ }^{1 *}$, Phung Xuan Son ${ }^{1 *}$, Kim Bao Giang ${ }^{2}$, Phan Thi Hai ${ }^{3}$, Doan \\ Thi Thu Huyen ${ }^{3}$, Luong Ngoc Khue ${ }^{3}$, Pham Thi Quynh Nga ${ }^{4}$, Nguyen Tuan Lam ${ }^{4}$, \\ Hoang Van Minh ${ }^{1}$, Le Thi Thanh Huong ${ }^{1}$
}

\begin{abstract}
Evidence shows that tobacco advertising and promotion activities may increase tobacco consumption and usage, especially in youth. Despite the regulation on prohibiting advertisement of any tobacco product, tobacco advertisement and promotion activities are still common in Vietnam. This article presents current exposure to tobacco advertising and promotion (TAP) among school children aged 13 to 15 years in Vietnam in 2014 and potential influencing factors. Data from the Global Youth Tobacco Survey 2014 in Vietnam covering 3,430 school aged children were used. Both descriptive and analytical statistics were carried out with Stata 13 statistical software. Binary logistic regression was applied to explain the exposure to TAP among youth and examine relationships with individual factors. A significance level of $p<0.05$ and sampling weights were used in all of the computations. In the past 30 days, $48.6 \%$ of the students experienced exposure to at least 1 type of tobacco advertising or promotion. Wearing or otherwise using products related to tobacco was the most exposure TAP type reported by students (22.3\%). The internet (22.1), points of sales (19.2) and social events (11.5) were three places that students aged 13-15 frequently were exposed to TAP. Binary logistic results showed that gender (female vs male) $(\mathrm{OR}=\mathbf{0 . 6 1}, 95 \% \mathrm{CI}$ : $0.52-0.71)$, susceptibility to smoking $(\mathrm{OR}=\mathbf{2 . 1 2}$, $95 \% \mathrm{CI}$ : 1.53 - 2.92),

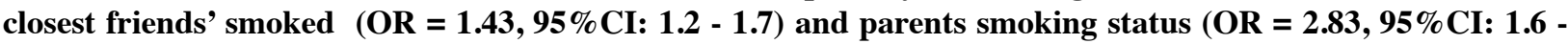
5.01) were significantly associated with TAP exposure among school-aged children. The research findings should contribute to effective implementation of measures for preventing and controlling tobacco use among students aged 13-15 in Viet Nam.
\end{abstract}

Keywords: GYTS - Viet Nam - tobacco advertising and promotion - influencing factors

Asian Pac J Cancer Prev, 17 Tobacco Prevention and Control in Vietnam Suppl, 49-53

\section{Introduction}

Tobacco advertising, promotion and sponsorship activities increase tobacco consumption and usage, especially engaging the youth familiar with tobacco. The WHO FCTC (Article 1) provides a definition of TAP as "any form of commercial communication, recommendation or action with the aim, effect or likely effect of promoting a tobacco product or tobacco use either directly or indirectly" (World Health Organization, 2003). The weight of evidence from cross-sectional, longitudinal, and experimental studies indicates a causal relationship between exposure to tobacco advertising and promotion (TAP) and youth smoking initiation (National Cancer Institute, 2008; Shah et al., 2008; Anderson et al., 2009; Sargent and Hanewinkel, 2009; Arora et al., 2012; Patel et al., 2012). In addition, longitudinal studies consistently suggested that exposure to tobacco advertising and promotion was associated with the likelihood that adolescents will start to smoke (Lovato, 2011).

Media have grown rapidly and are widely disseminated nowadays, and as a consequence media effects on tobacco used are complex and multidimensional. A study among 155.117 grade 7-9 middle school Chinese students in 31 provinces conducted in 2015 showed that in the past 30 days, $48.5 \%$ of the students had a chance to see advertisement or promotion programs on tobacco. Tobacco advertisement or promotion were most frequently seen on TV $(21.3 \%)$ among students, followed by outdoor billboard $(20.1 \%)$, at the stands for sale $(17.5 \%)$, and Internet $(15.6 \%)$. In addition, $4.6 \%$ of the students reported having kept the items related to brand logos of tobacco products; $2.0 \%$ reported having been offered a free tobacco product by tobacco company representatives; $69.7 \%$ reported having seen scenes related to smoking on TV/videos/movie screens (Xiao et al., 2015). Moreover, 
the study also revealed that smokers were more likely to feel smoking attractive than those who had not smoke (Xiao et al., 2015).

Vietnam is one of 15 leading countries having the highest rate of adult male smokers in the world (Ministry of Health, 2010). The Global Youth Tobacco Survey (GYTS) conducted in Vietnam in 2007 showed the prevalence of smoking among students aged 13-15 was $3.3 \%, 5.9 \%$ among males and $1.2 \%$ among females (Ministry of Health, 2007). This prevalence was low compare to other countries in Western Pacific such as Guam (25\%), Lao PRD (8\%), and Philippines (9\%) (World Lung Foundation, 2015), however, this issue should not be neglected because the tobacco industry in Vietnam has been investing extensively to promote smoking among adolescents even though Vietnam applied the Tobacco Control Law, in which, TAP had prohibited (VN National Assembly, 2012b; VN National Assembly, 2012a).

Prevention and control of tobacco use are priority public health issues in Vietnam, especially regarding school-aged students. Scientific information on exposure to tobacco advertising and promotion among youth and factors influenced these exposure should increase our understanding to contribute to the combat against the tobacco use problem.

\section{Materials and Methods}

\section{Data source}

Data used in this paper were obtained from the Global Youth Tobacco Survey (GYTS) conducted in Vietnam in 2014. The Viet Nam's GYTS 2014 is a school-based cross-sectional survey with secondary school and high school children aged 13-15 (grades of 8-10). 13 provinces represented for 6 geographic areas in Vietnam were selected by US Center for Disease Control (CDC). Two-stage cluster sample design was used to produce a representative sample of students in grades 8-10. A total of 3430 school children aged 13-15 years were selected for the survey. More detailed information can be found in the method paper (Giang et al., 2016).

\section{Measurements}

GYTS survey included core questionnaires that provided by the CDC; countries may add more specific questions based on the local situation and context. 6 types of exposure to TAP among school aged children were defined through 6 questions: (1) During the past 30 days, did you see any advertisement or promotion on tobacco product at point of sale such as store, shops...?; (2) During the past 30 days, did you see any advertisement on tobacco products at sport events, concerts, community events or social gatherings?; (3) Have you ever used or wear something such as lighter, t- shirt, hat or sunglasses... with Tobacco Company or tobacco product name and branch?; (4) During the past 30 days, did you see any advertisement on tobacco products on the internet?; (5) Have you ever receive the voucher at any shop or tobacco companies when buying tobacco products?; and (6) Has any person working for tobacco company ever invite you a free tobacco product?. Exposure to TAP was defined as a student answered "yes" to any type of TAP listed above.

Independent variables included: (1) Ever smoke status: ever smoke or never smoke any kind of tobacco (cigarette, shisha, E-tobacco, smokless...); (2) Susceptibility to smoking: based on 2 question: (a) "If 1 of your best friends offered you a cigarette, would you smoke it?", (b) "During the next 12 months, do you think you will smoke any form of tobacco product?". Possible responses were "definitely not," "probably not," "probably yes," and "definitely yes." Students who had never smoked and answered "definitely not" to both above questions were considered to be non-susceptible; all other students were considered to be susceptible; (3) Demographic variables: age; sex; geographical region; parents smoking status; closest friend smoking status.

\section{Statistical analysis}

Descriptive and statistical analyses with percentages and $95 \%$ confidence interval $(\mathrm{CI})$ were performed using IBM SPSS 22.0. The relationship between independent variables were conducted. Logistic regression modeling was used to identify what variables associated with exposure to tobacco advertising and promotion. A significance level of $\mathrm{p}<0.05$ and sampling weights were used in all of the computations.

\section{Ethical considerations}

The study was presented and discussed among those who are in charge of health research at the Ministry of Health and provincial authorities to get approval. Approval was also received from teachers, representatives of parents and students before carrying out survey.

\section{Results}

Altogether 3,430 school children aged 13-15 years participated in the survey, $49.1 \%$ males and $50.9 \%$ females. The prevalence of tobacco smoking among the students was $3.5 \%, 6.3 \%$ among males and $0.9 \%$ among females (Giang et al., 2016).

The prevalence of students who ever tried or used tobacco product was $12.3 \%$, and the figure for those susceptible to smoking was around $17.6 \%$. There were $55.5 \%$ of parents not smoking and $42 \%$ either father or mother smokes with just $2.5 \%$ of both parents smoking. The percentage of students not having a close friend who smoked was double that for students have close friend smoking (66.6\% compared to $33.4 \%$ ).

Figure 1 presented types of exposure to TAP from research subjects. $22.3 \%$ of students aged 13-15 wear or used products related to tobacco products, such as T-shirts, caps, lighters that had tobacco brand-name or tobacco logo printed. The results also revealed that tobacco advertisement or promotion attracted students most on the internet (22.1\%), followed by at the vendors/ Shops (19.2\%). Exposure to TAP at social events such as sport, fashion events were also reported but not usual with $11.5 \%$. Direct exposure to TAP such as inviting by TI staff and receiving coupons were not prevalent, accounted for $3 \%$ and $4.5 \%$ respectively.

The multiple exposure to TAP was showed in the 


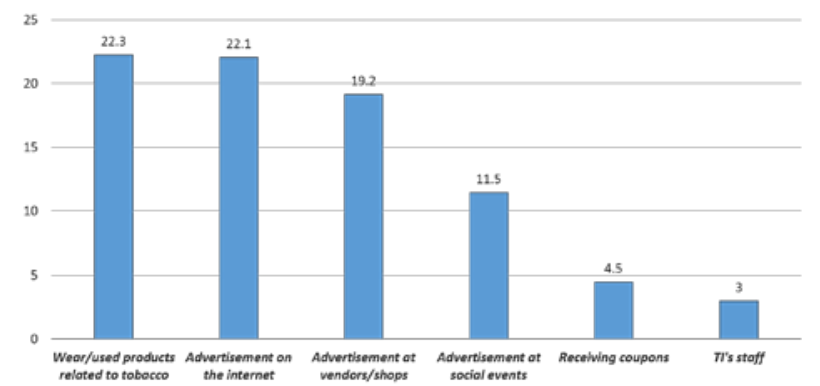

Figure 1. Weighted Prevalence of Type of Exposure to Tobacco Advertising and Promotion, GYTS Vietnam 2014

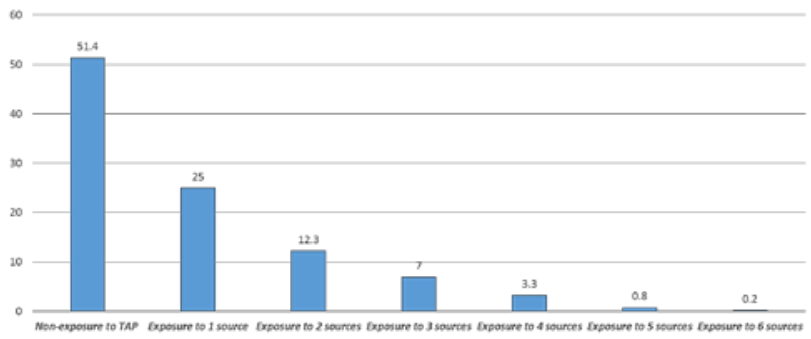

Figure 2. Weighted Distribution of Level of Exposure to Tobacco Advertising and Promotion Sources, GYTS Vietnam 2014

Table 1. Logistic Regression Analysis of Exposure to Tobacco Advertising and Promotion Channels and Selected Factors, GYTS, Vietnam, 2014

\begin{tabular}{|c|c|c|}
\hline \multirow{2}{*}{ Characteristic } & \multicolumn{2}{|c|}{ Exposure to TAP } \\
\hline & OR & $95 \% \mathrm{CI}$ \\
\hline \multicolumn{3}{|l|}{ Region } \\
\hline North & 1 & 1 \\
\hline Centre & 1 & $0.73-1.04$ \\
\hline South & 1 & $0.86-1.23$ \\
\hline Age, $y$ & 1 & $0.94-1.13$ \\
\hline \multicolumn{3}{|l|}{ Gender } \\
\hline Male & 1 & 1 \\
\hline Female & 0.61 & $0.52-0.71$ \\
\hline \multicolumn{3}{|l|}{$\begin{array}{l}\text { Ever smoke any tobacco prod- } \\
\text { ucts }\end{array}$} \\
\hline No & 1 & 1 \\
\hline Yes & 0.73 & $0.5-1.06$ \\
\hline \multicolumn{3}{|l|}{ Susceptibility to smoking } \\
\hline No & 1 & 1 \\
\hline Yes & 2.12 & $1.53-2.92$ \\
\hline \multicolumn{3}{|l|}{ Parents smoking status } \\
\hline Neither parent smokes & 1 & 1 \\
\hline $\begin{array}{l}\text { Either father or mother } \\
\text { smokes }\end{array}$ & 1.06 & $0.9-1.24$ \\
\hline Both parents smoke & 2.83 & $1.6-5.01$ \\
\hline \multicolumn{3}{|l|}{ Closest friends' smoking status } \\
\hline $\begin{array}{l}\text { Do not have closest friends } \\
\text { who smoke }\end{array}$ & 1 & 1 \\
\hline $\begin{array}{l}\text { Have closest friends who } \\
\text { smoke }\end{array}$ & 1.43 & $1.2-1.7$ \\
\hline
\end{tabular}

Figure 2. One source of TAP exposure was seen popularly with the highest percentage of $41.5 \%$, followed by two sources and three sources of TAP exposure with $22.7 \%$ and $11.3 \%$, respectively. As can be seen clearly that the trend of number TAP exposure sources was falling down. The percentage of students never exposed to TAP was $16.5 \%$, in other words, $83.5 \%$ of students aged $13-15$ was exposure to at least 1 source of tobacco advertisement or promotion.

Table 1 summarizes the findings from binary logistic regression analysis with weighted sample between influenced factors and TAP exposure status. Region, age and gender were included to calculate adjusted odd ratio. Significantly lower odds of TAP exposure was found among female students comparing to male students (OR $=0.61$, 95\%CI: 0.52-0.71). Those who had susceptibility to smoking had higher odds of exposure to TAP (OR = 2.12,95\%CI: 1.53 - 2.92). Also, closest friend and parent smoking history increased the odds of TAP exposure among students. Students who had both parents smoke had higher odds to exposure to TAP comparing with those whose parents did not smoke $(\mathrm{OR}=2.83,95 \% \mathrm{CI}$ : 1.6 - 5.01). Having closest friends smoked increased 1.43 times of odds exposure to TAP compared to student who did not have closest friends smoked $(\mathrm{OR}=1.43,95 \% \mathrm{CI}$ : 1.2 - 1.7).

\section{Discussion}

The study result shows that $48.6 \%$ of students aged 13-15 had a chance to see advertisement or promotion programs on tobacco. This prevalence was similar with what found in a study among 155,117 school aged children in 31 provinces in China (Xiao et al., 2015). Regarding to types of TAP exposure, the findings from this study showed that except the increase from $12 \%$ to $22.3 \%$ in exposure to products that had tobacco brand name or logo printed, a downward trend was presented in all other kind of TAP exposure comparing with the TAP figure showed in 2007.

TAP exposure at the point of sales decreased sharply from $42.7 \%$ in 2007 to $19.2 \%$ in 2014 , while that at outdoor events was reduced from $53.6 \%$ to $11.5 \%$. In addition, two traditional TAP which were offered coupons at point of sales and free tobacco product by tobacco company representatives were lower than the figure showed in 2007 where $6.6 \%$ and $9.5 \%$ students in Viet Nam GYTS 2007 reported having exposure to these types of TAP respectively (Ministry of Health, 2007).

Compared with other countries, this pattern was quite different from China where tobacco advertisement or promotion were most frequently seen on TV (21.3\%), followed by outdoor billboard $(20.1 \%)$, at the stands for sale $(17.5 \%)$, and Internet $(15.6 \%)$ (Xiao et al., 2015) and was lower compared to the study results at 20 low and middle income countries (LMICs) where outdoor community events were more important $(30.6 \%$ in Rwanda to $79.4 \%$ in the Philippines (Agaku et al., 2013).

The positive figure of TAP exposure shown in this study could be a result of various tobacco control programs 
that had been implemented within recent year, some could be listed as the Tobacco Control Law that was approved in June 2012 by the National Assembly and enacted in May 2013. In which, article 9 strictly prohibits all kinds of tobacco advertising and promotion (VN National Assembly, 2012b). In addition to that, the advertisement of tobacco is also prohibited in Article 7 of the Law on Advertisement (VN National Assembly, 2012a).

In term of exposure level, we found that students in Viet Nam exposed to frequently 1 or 2 TAP sources (25\% and $12.3 \%$, respectively). This finding was lower than other countries such as China (Xiao et al., 2015), Thailand, Australia (Li et al., 2009), India (Sinha et al., 2014) or USA (Agaku and Ayo-Yusuf, 2014). Fewer source of TAP exposure could be a positive outcome of the various efforts made by Viet Nam tobacco control agencies within recent years.

Across the board, girls showed lower risk for smoking (Babar et al., 2010), the same pattern was found in this paper, female students had a lower odds of TAP exposure comparing to male students $(\mathrm{OR}=0.82,95 \% \mathrm{CI}$ : 0.67 - 1.00). In other hand, we did not found a significant association between region and TAP exposure among students aged 13-15. This finding was difference from the study of Yang et al across six cities in China where presented the overall levels of noticing advertisements varied considerably by city.(Yang et al., 2010). It could be explained by the characteristic of Viet Nam where the North, the Centre and the South share a quite similar culture and social development.

Friends and parents were found as two main sources that had impact the adolescent behaviors (Gibbon et al., 2008). Peer influences can often be negative and the effects of peer pressure can range from disturbing to dangerous. Usually teens who belong to a peer group where most of the friends are smokers, are more likely to smoke (Go et al., 2010). Close friends have greater power to influence the behaviors of peers, as well as best friends. In addition, not only friends but also parents represent an important role in the development of adolescents (Piko, 2010). The monitor and behaviors of parents could be found as an important factor in reducing risk behaviors of youth developments (Gina Tomé et al, 2012). The same finding was found in this paper, closest friends and smoking behavior of parents increased the odds of exposure to TAP among school-aged children.

In summary, we found that the prevalence of TAP exposure among school-aged children in Viet Nam was still high (48.6\%). Even though the study results on the types of TAP exposure and level of exposure revealed a positive sign of TAP exposure situation in Viet Nam as a consequence of various efforts made by Viet Nam tobacco control agencies within recent years, the results also presented a high prevalence of TAP exposure on the internet and at the point of sales among student aged 13-15, especially the exposure through products related to tobacco, such as T-shirts, lighters, caps...that had tobacco logo or brand name printed. It means that monitoring activities in these types of TAP need to pay more attention in the future. In addition, we also found that gender, susceptibility to smoking, parents smoking status and friends' smoking status were significantly associated with student's TAP exposure status. These findings give scientific evidences for effectiveness implementation on preventing and controlling tobacco use among student aged 13-15 in Viet Nam.

We need to note some limitations of our data. The GYTS relies on self-completion of the questionnaires. The accuracy of reporting in this study is not known. The GYTS applied only to school students. The survey did not include those who were outside the school environment.

\section{Acknowledgements}

We thank the VINACOSH (Vietnam Steering Committee on Smoking and Health) and GYTS team of Vietnam for making these data available. We also thank WHO's Tobacco Free Initiative (TFI) and CDC's Office on Smoking and Health for providing technical assistances. We also acknowledge the financial supports and coordination of the Hanoi School of Public Health and the Tobacco Control Research group of Vietnam Tobacco Control Fund.

\section{References}

Agaku I, Adisa A, Akinyamoju A, et al (2013). A cross-country comparison of the prevalence of exposure to tobacco advertisements among adolescents aged 13-15 years in 20 low and middle income countries. Tobacco Induced Diseases, 11.

Agaku I, Ayo-Yusuf O (2014). The effect of exposure to protobacco advertising on experimentation with emerging tobacco products among U.S. adolescents. Health Educ Behav, 41, 275-80.

Arora M, Gupta VK, Nazar GP, et al (2012). Impact of tobacco advertisements on tobacco use among urban adolescents in India: results from a longitudinal study. Tob Control, 21, 318-24.

Babar AA, Stigler MH, Perry CL, et al (2010). Tobacco-use psychosocial risk profiles of girls and boys in urban India: implications for gender-specific tobacco intervention development. Nicotine Tob Res, 12, 29-36.

Giang KB, Minh HV, Hai PT and et al (2016). Methodology of global youth tobacco use survey (GYTS) in Viet Nam, 2014. Asian Pac J Cancer Prev, 17 Tobacco Prevention and Control in Viet Nam Suppl, 11-15.

Gibbon XF, Pomery, AE, Gerrard M (2008). Cognitive social influence - moderation, mediation, modification, and the media In MJ Prinstein \& KA Dodge (Eds.). Understanding Peer Influence in Children and Adolescents. New York: The Guilford Press, 45-71.

Gina Tomé MG, Camacho I, Simões C, Alves Diniz J (2012). The effect of peer group influence and the role of parents on adolescent behaviors Pakistan. J Psychol, 43, 35-6.

Go MH, Green HD Jr, Kennedy DP, Pollard M, Tucker JS (2010). Peer influence and selection effects on adolescent smoking. Drug Alcohol Dependence, 109, 239-42.

Li L, Yong HH, Borland R, et al (2009). Reported awareness of tobacco advertising and promotion in China compared to Thailand, Australia and the USA. Tob Control, 18, 222-7.

Lovato C WA, Stead LF, (2011). Impact of tobacco advertising and promotion on increasing adolescent smoking behaviours. Cochrane Database Syst Rev, 10.

Ministry of Health (2007). Report of global youth tobacco use 

survey.

Ministry of Health (2010). Report of global adult tobacco use survey.

Patel D, Kassim S, Croucher R (2012). Tobacco promotion and availability in school neighborhoods in India: a crosssectional study of their impact on adolescent tobacco use. Asian Pac J Cancer Prev, 13, 4173-6.

Piko FBH (2010). Parent, school, and peer-related correlates of adolescents' life satisfaction. Children Youth Services Rev, 32, 1479-82.

Sargent J, Hanewinkel R (2009). Comparing the effects of entertainment media and tobacco marketing on youth smoking in Germany. Addict, 104, 815-23.

Shah PB, Pednekar MS, Gupta PC, et al (2008). The relationship between tobacco advertisements and smoking status of youth in India. Asian Pac J Cancer Prev, 9, 637-42.

Sinha DN, Palipudi KM, Oswal K, et al (2014). Influence of tobacco industry advertisements and promotions on tobacco use in India: findings from the Global Adult Tobacco Survey 2009-2010. Indian J Cancer, 51, 13-8.

VN National Assembly (2012a). Law on Advertisement.

VN National Assembly (2012b). Law on Tobacco Control.

World Health Organazation (2013). Tobacco advertising, promotion and sponsorship in China. China WHO representative.

World Lung Foundation (2015). Tobacco use among youth. The Tobacco Atlas.

Xiao L, Yang J, Zhao L, et al (2015). Exposure to tobacco advertisement and promotion programs among Chinese middle school students: a cross-sectional survey. Zhonghua Liu Xing Bing Xue Za Zhi, 36, 309-13.

Yang Y, Li L, Yong HH, et al (2010). Regional differences in awareness of tobacco advertising and promotion in China: findings from the ITC China Survey. Tob Control, 19, 117-24. 